\title{
Hydrolytic stability of polylactide stereocomplex microparticles containing metal ions
}

\section{Edyta Wojtczak ${ }^{1} \cdot$ Tadeusz Biedroń $^{1} \cdot$ Melania Bednarek ${ }^{1}$}

Received: 3 October 2017 / Revised: 11 January 2018 / Accepted: 6 July 2018 / Published online: 11 July 2018 (c) The Author(s) 2018

\begin{abstract}
Polylactide (PLA) stereocomplexes (SCs) were prepared from low molecular weight PLLA and PDLA with terminal carboxyl groups in the presence and in the absence of calcium oxide being a donor of metal ions. Only the stereocomplexation performed in the presence of metal ions causing PLA macromolecules preorganization resulted in the $\mathrm{SC}$ formation in a form of spherical microparticles (microspheres). Hydrolyses of microspheres containing $\mathrm{CaO}$ and the $\mathrm{SC}$ without $\mathrm{CaO}$ were performed in a phosphate buffer $\mathrm{pH}=7.4$ at temperatures 37 and $50{ }^{\circ} \mathrm{C}$. The rate of hydrolytic degradation of SCs was studied and compared to find the effect of the metal ions presence. The results of the hydrolysis were analyzed by the observation of polymer samples using scanning electron microscopy and infrared spectroscopy, also by differential scanning calorimetry measurements.
\end{abstract}

Keywords Hydrolysis · Degradation · Polylactide $\cdot$ Stereocomplex $\cdot$ Microspheres · Metal ions

\section{Introduction}

One of the main features of polylactide materials designed for biomedical and pharmaceutical applications is their ability to degradation in a controlled manner in the biological environment. The mechanism of hydrolytic degradation and its time scale may vary for different polymeric materials, and they depend on parameters related to the environment such as $\mathrm{pH}$ and degradation temperature [1-5]. For the PLA material working at specific conditions, its susceptibility to hydrolytic degradation can be

Electronic supplementary material The online version of this article (https://doi.org/10.1007/s0028 9-018-2432-9) contains supplementary material, which is available to authorized users.

Melania Bednarek

bednarek@cbmm.lodz.pl

1 Centre of Molecular and Macromolecular Studies, Polish Academy of Sciences, Sienkiewicza 112, 90-362 Lodz, Poland 
influenced by the molecular weight of the polymer, the architecture, the presence of comonomer units or the crystallinity [6-9].

Apart from the manipulation by aforementioned parameters, the modification of hydrolytic degradation process can be achieved by the preparation of PLA stereocomplex from both PLLA and PDLA stereoisomers. It is known that PLA stereocomplex has better thermomechanical properties than stereoisomers $[10,11]$. Melting temperature of PLA SC is about $50{ }^{\circ} \mathrm{C}$ higher, and also mechanical properties are improved which is attributed to the increased intermolecular crystallization (resulting in a larger number of tie chains between crystallites) [11]. Higher crystallinity of stereocomplex in comparison with the enantiomeric polymer has an effect on its degradation. The hydrolytic degradation process of PLA stereocomplex was a subject of several studies [8, 12-15]. It was found that the degradation rate of PLLA/ PDLA SC was lower than the degradation rate of PLLA which can be assigned to strong secondary interactions between complementary macromolecules of SC and a higher degree of crystallinity of SC material [14].

PLA stereocomplex can be prepared in the melt or in solution. When prepared in solution by the application of such methods as solvent evaporation, precipitation, lowering solvent temperature or spray droplet atomization it may crystallize in a form of microparticles with specific morphology depending on conditions. Several articles appeared concerning the study of the morphology of PLA SC crystallized from solution [11, 16-21].

The contributions from our group [18, 20, 21] were focused on stereocomplexation of medium molecular weight PLAs containing ionic end groups. We proved that the presence of ionic end groups (imidazolium or carboxylate groups were introduced) facilitated the PLA macromolecules preorganization leading to spherical microparticles with high regularity $[18,21]$. The influence of external conditions as, e.g., a type of the solvent, the polymer concentration as well as the molecular weight and the number of ionic end groups on the size and the regularity of microspheres was studied. In the case of carboxylate end groups, microparticles were prepared in the presence of metal ions which enabled ionization of initial carboxyl groups. Then, metal ions were present in the formed microparticles (metal oxide was used as a metal ions donor in the cited article [21]).

The phenomenon of spontaneous PLA microspheres formation upon PLA stereocomplexation and the possibility of controlling microspheres' size and regularity suggested their application for the encapsulation of biologically active compounds. If designed as drug delivery systems (DDS) [22-25], PLA microspheres should undergo hydrolytic degradation and this degradation should be tunable. Thus, for applications as drug delivery systems, the hydrolysis profiles of drug-containing polymeric vesicles or microspheres are very important.

There is a broad literature concerning DDS based on one PLA stereoisomer (mainly PLLA or its copolymers with other monomers) [26-36] where the degradation and drug release from polymeric matrix were also studied. Some publications also describe DDS consisting in part of PLA stereocomplex (PLA SC) [17, 19, 37-40] which introduces the stabilizing effect. Thus, the microparticles are more stable, but it is necessary to remember that this stabilization effect is coupled with changed (in comparison with PLLA) degradation profile. 
In the presented work (being an extension of the mentioned study on SC microparticles formation [21]), we investigated a process of hydrolytic degradation of microspheres prepared by spontaneous stereocomplexation of PLA with carboxyl end group in the presence of calcium ions ( $\mathrm{CaO}$ was used as a donor of cations). The presence of calcium ions (calcium oxide is no longer in its crystalline form when the interaction with carboxyl groups is considered [21]) should influence hydrolytic degradation of stereocomplex. The effect of traces of metals on the hydrolytic degradation of one PLA stereoisomer has been already studied [41], however not for stereocomplex, which additionally was in a specific form, i.e., microspheres. On the other hand, although the hydrolysis of stereocomplex in a form of microparticles was also investigated [15], that study concerned high molecular weight PLA $(\sim 130,000)$ which did not contain metal ions, and hydrolysis was stopped reaching $M_{n}$ values close to those of our starting polymers.

It seems that in a present study, both the presence of metal cations inside PLA material and the spherical shape of PLA microparticles could influence their hydrolytic degradation.

The influence of calcium cations inside microparticles was determined by the comparison of the results of both degradations - the stereocomplex obtained in the presence and in the absence of calcium oxide. Additionally, we compared these degradation processes with the degradation of one stereoisomer without any additive.

\section{Experimental part}

\section{Materials}

L,L-Lactide (LLA) (BoehringerIngelheim, Germany) and D,D-lactide (DLA) (Purac, 99\%) were purified by crystallization from dry 2-propanol and sublimation. Glycolic acid (GA) (99\%, Aldrich), trifluoromethanesulfonic acid (triflic acid) (98\%, Aldrich), 1,4-dioxane (pure, Chempur) and THF (HPLC, Baker), calcium oxide (99\%, Aldrich) were used as received. Phosphate buffer, $\mathrm{pH}=7.4$, was prepared from Hydrion Buffers (MicroEssentialLab).

\section{Synthesis of PLA-COOH}

L-Lactide (LLA) or D-lactide (DLA) (2.0 g, $13.9 \mathrm{mmol})$ and glycolic acid (GA) $(0.061 \mathrm{~g}, 0.8 \mathrm{mmol})$ were placed in a Schlenk tube, which was degassed, filled with argon and placed in an oil bath heated to $105^{\circ} \mathrm{C}$. After monomer has melted, triflic acid $(1 \mu \mathrm{L}, 0.011 \mathrm{mmol})$ was added with a syringe through the rubber septum. Polymerizations were conducted at $105{ }^{\circ} \mathrm{C}$ with stirring for $1 \mathrm{~h}$. Obtained solid polymers were crushed, dissolved in $\mathrm{CH}_{2} \mathrm{Cl}_{2}$, precipitated into methanol and filtered. Products were dried under vacuum and characterized by SEC, ${ }^{1} \mathrm{H}$ NMR, and DSC methods. 


\section{Preparation of PLA stereocomplex}

$0.6 \mathrm{~g}$ of PLLA and $0.6 \mathrm{~g}$ of PDLA were dissolved separately in $6 \mathrm{ml}$ of a solvent (1,4-dioxane or THF). Then, an equimolar amount of calcium oxide in respect to $-\mathrm{COOH}$ groups in the polymer was added. The suspensions were stirred (each separately) for $3 \mathrm{~h}$, then were quickly mixed together and left for $24 \mathrm{~h}$. During this time, the stereocomplex slowly precipitated. After the separation precipitated stereocomplex was dried in air, next in vacuum and was analyzed by SEM and DSC.

\section{Hydrolysis procedure}

Small portions of prepared stereocomplex (about $0.06 \mathrm{~g}$ ) were weighed into 8-mL vials to which $6 \mathrm{~mL}$ of phosphate buffer $(\mathrm{pH}=7.4)$ were added. Vials (closed with taps) were placed in a hotplate with holes heated to 37 or $50{ }^{\circ} \mathrm{C}$. Each vial contained separate sample which was removed from the heating plate after predetermined hydrolysis time and was analyzed (mainly the solid stereocomplex after its separation or both—-stereocomplex and hydrolysis medium).

\section{Instrumentation}

${ }^{1} \mathrm{H} N M R$ spectra of polylactides were recorded in $\mathrm{CDCl}_{3}$ using a Bruker DRX500 instrument operating at $500 \mathrm{MHz}$.

Size-exclusion chromatography (SEC) was performed using an Agilent Pump 1100 Series with Agilent G1379A Degasser and a set of two PL-Gel 51 mixedC columns. Wyatt Optilab Rex interferometric refractometer (Wyatt Technology Corp., Santa Barbara, USA) was used as a detector. Dichloromethane was used as an eluent at a flow rate of $0.8 \mathrm{~mL} \mathrm{~min}^{-1}$ at room temperature. The system was calibrated according to polystyrene standards.

Differential scanning calorimetry (DSC) analysis was performed under nitrogen at a heating and cooling rate of $10{ }^{\circ} \mathrm{C} / \mathrm{min}$ on DSC 2920 Modulated TA Instrument. Both temperature and heat flow were calibrated with indium.

Scanning electron microscopy (SEM) images were taken using Jeol JSM$5500 \mathrm{LV}$ apparatus working in the secondary electron mode with an accelerating voltage of $10 \mathrm{kV}$. The samples were prepared by fixing onto carbon adhesive tape and covering with a conductive gold layer and were studied in a low vacuum.

FT IR measurements were performed on a ThermoScientific Nicolet 6700 FTIR instrument with an attenuated total reflectance Axiom accessory and an $\mathrm{MCT} / \mathrm{A}$ detector using a resolution of $2 \mathrm{~cm}^{-1}$.

Single particle optical sizing (SPOS) analysis was performed on an AccuSizer 780 AD Organic Compatible instrument (PSS-NICOMP, Santa Barbara, CA, USA) equipped with an automatic dilution system (auto dilution) in order to eliminate particle coincidence in the sensing photozone using water dispersion of PLA stereocomplex samples. 
Chemical ionization $(C I)$ mass spectra were recorded on a GCMS-QP2010 ULTRA instrument (Shimadzu, Kioto, Japan). The mass spectra were obtained using methane as the reagent gas and the following operating conditions: electron energy of $20 \mathrm{eV}$ and ion source temperature of $200{ }^{\circ} \mathrm{C}$. Samples were introduced via a direct insertion probe heated from 30 to $300{ }^{\circ} \mathrm{C}$.

$\mathrm{pH}$ measurements of hydrolysis medium were performed using $\mathrm{pH}-\mathrm{Meter} \mathrm{CP}-501$ (Elmetron, Poland) and a combination glass electrode EPS-1 with saturated $\mathrm{KCl}$ water solution as a reference electrolyte (Elmetron, Poland).

\section{Results}

\section{Preparation of PLA stereocomplexes}

Poly(L-lactide) and Poly(D-lactide) containing one hydroxyl and one carboxyl terminal groups used for the stereocomplex preparation were synthesized via bulk cationic polymerization initiated by glycolic acid [21]. Stereocomplexes in a form of microparticles were prepared by PLA stereocomplexation performed in a solution in the presence of calcium oxide as we described in our previous article [21]. Calcium oxide, in the equimolar amount to terminal carboxyl groups in PLA chain $([\mathrm{CaO}] /$ $[-\mathrm{COOH}]=1)$, was added to PLLA and PDLA solutions before their mixing. For comparative study, stereocomplex without $\mathrm{CaO}$ additive was also obtained. First hydrolysis experiments were performed at $37^{\circ} \mathrm{C}$, and SCs precipitated from dioxane (with and without $\mathrm{CaO}$ ) were used for this purpose. However, during experiments duration, it was found that much regular and smaller microspheres could be obtained by SC precipitation from THF [21]; thus, such microparticles were used for the fast complementary experiment of hydrolysis performed at $50{ }^{\circ} \mathrm{C}$. Polymers which were used for stereocomplexations are presented in Table 1. Figure 1 shows stereocomplexes morphologies.

Table 1 Polylactides used for stereocomplexations and obtained microparticles

\begin{tabular}{|c|c|c|c|c|}
\hline \multirow{2}{*}{$\begin{array}{l}\text { Solvent used for ste- } \\
\text { reocomplexation }\end{array}$} & \multirow{2}{*}{$\begin{array}{l}M_{n} \text { PLLA- } \\
\mathrm{COOH}^{\mathrm{a}}\end{array}$} & \multirow{2}{*}{$\begin{array}{l}M_{n} \text { PDLA- } \\
\mathrm{COOH}^{\mathrm{a}}\end{array}$} & \multicolumn{2}{|c|}{ Prepared stereocomplexes } \\
\hline & & & $\mathrm{CaO}$ additive & Microparticles diameter, $\mu \mathrm{m}^{\mathrm{b}}$ \\
\hline \multirow[t]{2}{*}{ Dioxane } & 2000 & 2050 & No & Not determined \\
\hline & & & Yes & Microspheres, 3.1 \\
\hline THF & 2100 & 2200 & Yes & Microspheres, 1.4 \\
\hline
\end{tabular}

${ }^{\mathrm{a}}$ Molecular weights were calculated from ${ }^{1} \mathrm{H}$ NMR spectra by the comparison of the intensities of signals corresponding to $-\mathrm{C}(\mathrm{O}) \underline{\mathrm{CH}}\left(\mathrm{CH}_{3}\right)-\mathrm{OH}$ end groups with those corresponding to $-\mathrm{C}(\mathrm{O}) \underline{\mathrm{CH}}\left(\mathrm{CH}_{3}\right)-\mathrm{O}-$ groups from the polymer backbone. Although SEC analysis was also performed for PLA polymers, it served only as a confirmation of monomodal molecular weight distribution no to calculate $M_{n}$ values which could be erroneous because of the calibration for PSt standards

${ }^{\mathrm{b}}$ Microspheres diameter was determined on the basis of single particle optical sizing measurements [21] (see results in Supplementary Information) 

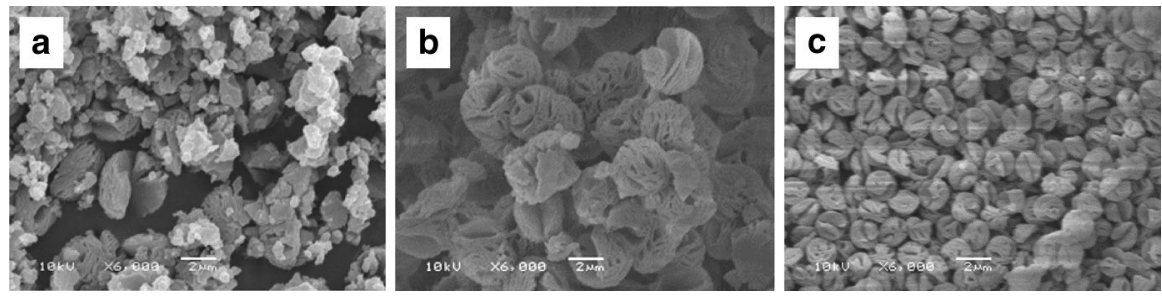

Fig. 1 SEM pictures of SCs obtained: $\mathbf{a}$ in dioxane without $\mathrm{CaO}, \mathbf{b}$ in dioxane with $\mathrm{CaO}$, $\mathbf{c}$ in $\mathrm{THF}$ with $\mathrm{CaO}$

\section{Hydrolytic degradation studies}

Hydrolytic degradation studies of biodegradable polymers can be performed using different protocols. The hydrolysis in buffered water solution (with different although stable $\mathrm{pH}$ ) performed at several temperatures is most often applied. Typically, the hydrolysis in the presence of phosphate buffer, $\mathrm{pH}=7.4$ at temperature $37{ }^{\circ} \mathrm{C}$ is performed. The hydrolysis medium can be systematically exchanged; however, hydrolysis conducted without changing of the hydrolytic environment allows to determine the effect of the presence of degradation products on further course of hydrolysis.

Our study on PLA microparticles susceptibility to hydrolytic degradation was performed in phosphate buffer with initial $\mathrm{pH}=7.4$ without changing hydrolysis medium at temperature $37{ }^{\circ} \mathrm{C}$. In order to find more parameters characterizing hydrolyzed system, the study was completed by the fast hydrolysis performed at $50{ }^{\circ} \mathrm{C}$. Both experiments were conducted during 16 weeks.

In the case of hydrolysis at $37{ }^{\circ} \mathrm{C}$, the stereocomplex precipitated under the same conditions but without calcium oxide was also investigated because it was interesting how the presence of metal ions influenced the hydrolytic degradation of microspheres. Additionally, the hydrolysis of starting PLLA stereoisomer (without $\mathrm{CaO}$ addition) was performed for comparison.

All samples separated from the suspension and dried on a vacuum line were weighted after predetermined hydrolysis time in order to calculate the weight loss. An attempt of the determination of molecular weights by SEC method indicated that the solubility of PLA SC was not sufficient to have the reliable values. (It was observed that part of polymer remained on a filter before the SEC measurement). SEC analysis of the soluble fraction resulted in multimodal molecular weight distribution what is visible in Fig. 2 presenting SEC curves of PLA stereocomplex prepared in the presence of $\mathrm{CaO}$ at different stages of its hydrolysis. Although SEC curves clearly showed the progress of hydrolysis, this analysis did not allow the calculation of $M_{n}$ values (especially in the case of using a calibration for polystyrene standards).

The results of the weight change and the DSC analysis of all samples subjected to hydrolysis at $37^{\circ} \mathrm{C}$ are shown in Table 2 . 
Fig. 2 SEC traces of PLA stereocomplex prepared in the presence of $\mathrm{CaO}$ at different stages of its hydrolysis at $37^{\circ} \mathrm{C}$

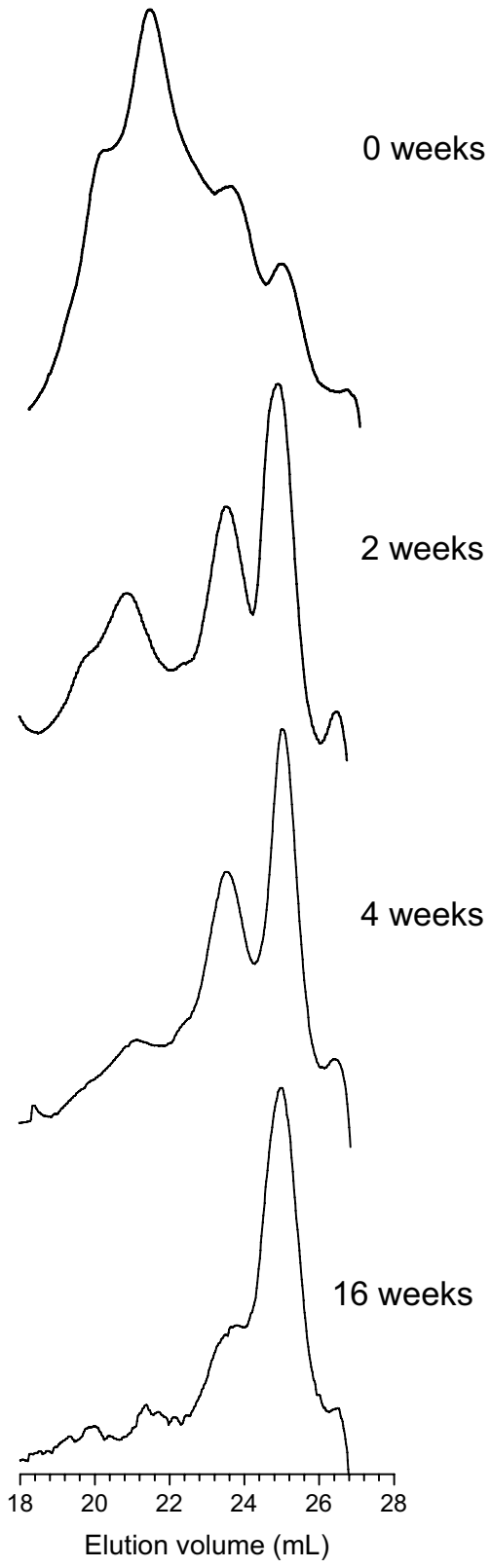

Thermal properties were analyzed from the first DSC run in order to include the effect of the sample history together with the SC self-organization into spherical microparticles (Fig. 3).

As expected prepared stereocomplexes had much higher melting temperatures $\left(\sim 216{ }^{\circ} \mathrm{C}\right.$ at the beginning) than PLLA $\left(159{ }^{\circ} \mathrm{C}\right)$. The values of SC melting 
Table 2 Results of the hydrolysis of microparticles obtained by stereocomplexation of PLA-COOH in dioxane in the absence and presence of $\mathrm{CaO}$, performed at $37^{\circ} \mathrm{C}$

\begin{tabular}{lllll}
\hline Sample & $\begin{array}{l}\text { Hydrolysis } \\
\text { time, weeks }\end{array}$ & Weight loss, $\%$ & DSC, I run & \multicolumn{1}{c}{${ }^{2} H_{m}, \mathrm{~J} \mathrm{~g}^{-1}$} \\
\hline Stereocomplex & 2 & & ${ }^{\circ} \mathrm{C}$ & 101.5 \\
& 4 & $\sim 0$ & $215.6(210.0206 .6)$ & 107.1 \\
& 8 & 1.6 & 208.1 & 106.7 \\
Stereocomplex with CaO & 16 & 3.5 & 205.2 & 103.5 \\
& 2 & 12.0 & $216.8(210.5205 .0)$ & 63.2 \\
& 4 & 6.2 & $212.8(208.7)$ & 76.4 \\
PLLA & 8 & 8.1 & 208.2 & 73.5 \\
& 16 & 9.9 & 206.4 & 53.9 \\
& 2 & 16.8 & 159.4 & 73.6 \\
& 4 & 3.7 & 158.7 & 79.1 \\
& 8 & 4.3 & 158.3 & 79.5 \\
& 16 & 5.5 & 158.2 & 74.0 \\
\hline
\end{tabular}

Additionally, results of hydrolysis of starting polylactide are shown

${ }^{\mathrm{a}}$ n.d. not determined

temperature were almost not influenced by the presence of calcium compound inside and hence by the self-organization of PLA macromolecules into spherical microparticles. In DSC curves of SC microparticles at the beginning of hydrolysis, we can notice one or two overlapped melting peaks before the main peak which disappears in DSC curves recorded for hydrolysis product at later stages. This observation could mean that some other crystalline forms existed apart from typical stereocomplex crystals, and these forms were destroyed during hydrolysis. Differently to melting temperature behavior, melting enthalpy of stereocomplex not containing calcium oxide is higher than that of $\mathrm{SC}$ with $\mathrm{CaO}$ additive which means that the initial degree of crystallinity is lower for $\mathrm{SC} / \mathrm{CaO}$ microparticles. The melting enthalpy value for $100 \%$ crystalline stereocomplex (prepared from high molecular PLA) reported in a literature is equal to $142 \mathrm{~J} / \mathrm{g}$ (145 J/g by other authors) [16], whereas one of the reported melting enthalpies of PLLA homocrystallities is equal to $93 \mathrm{~J} / \mathrm{g}$ [16].

As it is known that hydrolytic degradation starts from amorphous regions [42], thus it could be expected that PLA stereocomplex with lower crystallinity (in a form of microparticles containing $\mathrm{CaO}$ ) should degrade easier (faster) than $\mathrm{SC}$ alone with higher crystallinity.

With increasing time of the exposure to hydrolytic medium, the crystallinity of both $\mathrm{SCs}$ (with and without $\mathrm{CaO}$ ) initially increases which is a known phenomenon [42] and primarily is due to higher proportion of crystalline phase (after removing of amorphous one) and to the increased mobility of shorter polymer chains facilitating in this way crystallization. Only after significant chain shortening at later stages of hydrolysis process, the crystallinity decreases.

The progress of hydrolytic degradation of both stereocomplexes with time followed by the weight loss of the samples is presented in Fig. 4. 


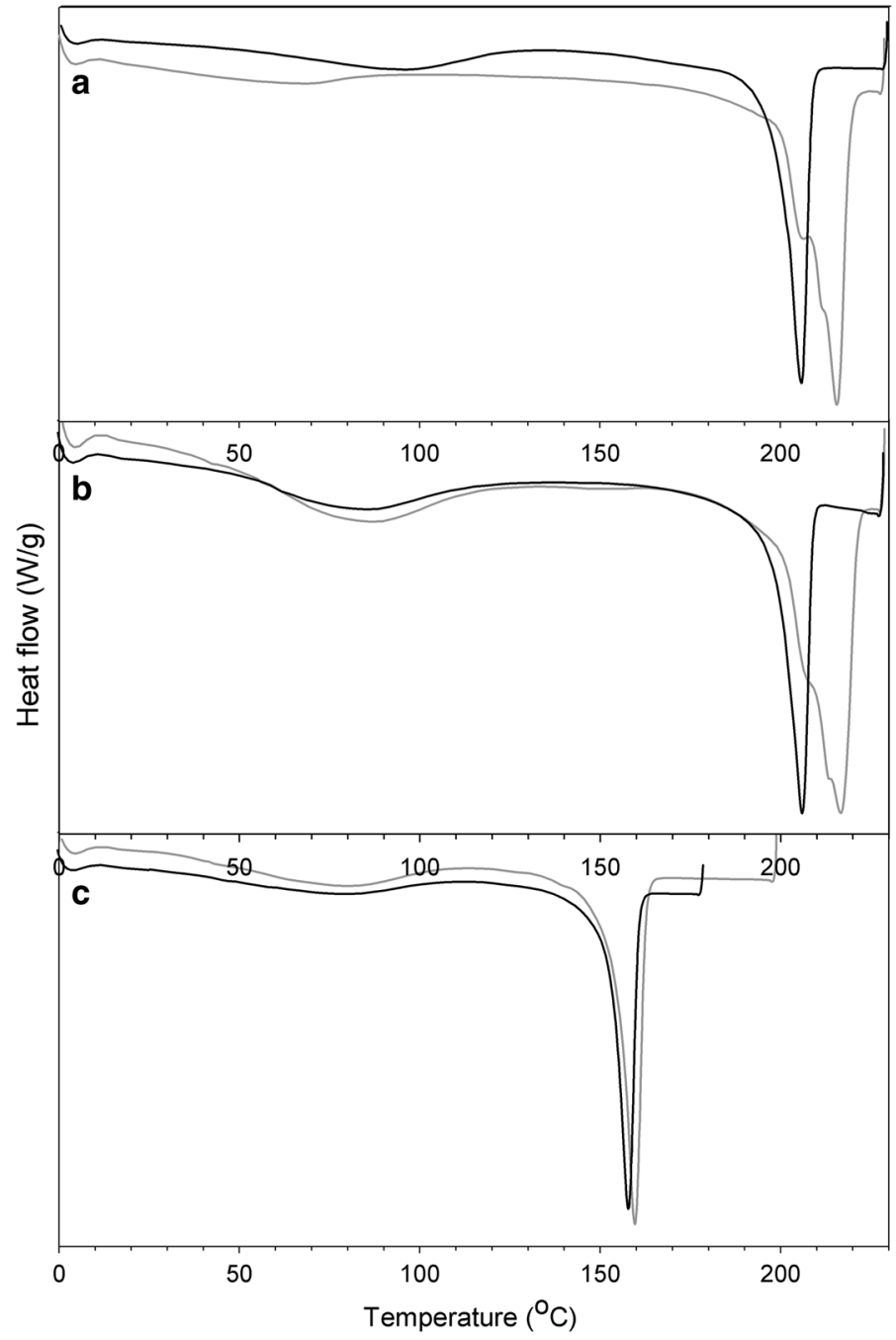

Fig. 3 DSC curves recorded for stereocomplexes hydrolyzed at $37{ }^{\circ} \mathrm{C}$ : a SC without $\mathrm{CaO}$ additive, b SC with $\mathrm{CaO}$ and $\mathbf{c}$ PLLA used for stereocomplexation; gray line corresponds to the sample after 2 weeks of hydrolysis, black line-the sample after 16 weeks of hydrolysis

As it is visible from presented in figure plots, $\mathrm{SC}$ with $\mathrm{CaO}$ degrades faster than SC without metal salt and it degrades faster than PLLA stereoisomer alone. The results of weight loss measurements are consistent with those from DSC analysis, that is stereocomplex with lower crystallinity degrades faster. It seems that the presence of $\mathrm{CaO}$, apart from lowering the crystallinity, may have also another effect. By ionization of carboxyl groups at PLA chain ends, the swelling of the polymer was pronounced; thus, water easier penetrated polymer material [12]. Faster degradation was observed especially at the beginning of hydrolysis 


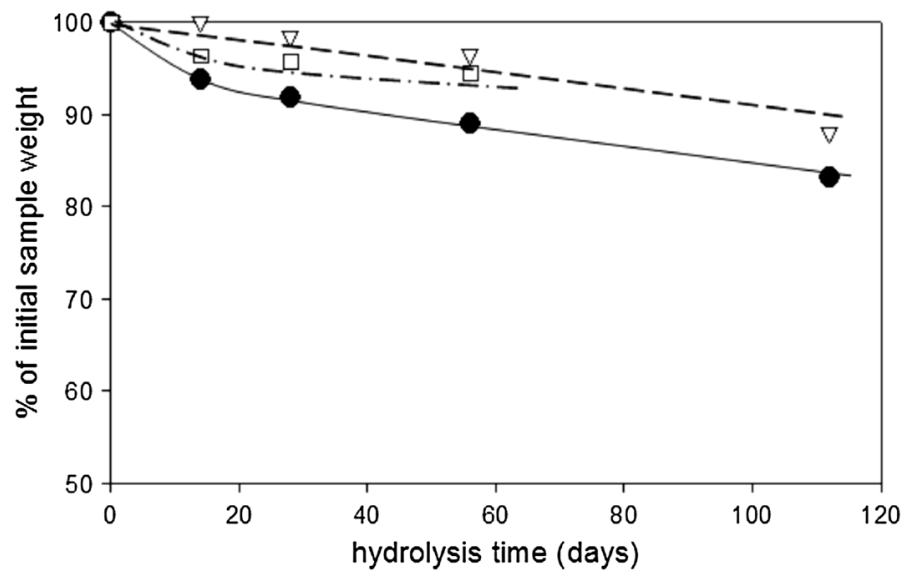

Fig. 4 The dependence of weight loss on time for SC/CaO (solid line), SC alone (dashed line) and PLLA (dashed-dotted line) during hydrolysis performed at $37^{\circ} \mathrm{C}$

experiment when $\mathrm{Ca}^{2+}$ cations still remained inside (water penetration did not cause advanced leaching of cations). Summarizing the weight loss results, it appeared that during 16 weeks $(\sim 2,5$ months) of hydrolysis experiment PLA SC microspheres containing $\mathrm{Ca}^{2+}$ lost about $15 \%$ of the initial weight.

The observed behavior of SC microparticles may be very useful in the potential application as a delivery system for biologically active compounds. Thus, the metal salt additive not only promotes the formation of PLA microparticles [21], but it could also facilitate the decomposition of drug carriers enabling the release of the entrapped pharmaceutical agent.

To obtain more information on hydrolysis products, additional faster hydrolysis was performed at higher temperature $\left(50^{\circ} \mathrm{C}\right)$ and with smaller PLA SC microspheres prepared in THF. The results are presented in Table 3.

Table 3 Results of the hydrolysis of microspheres obtained by stereocomplexation of PLA-COOH in $\mathrm{THF}$ in the presence of $\mathrm{CaO}$, performed at $50{ }^{\circ} \mathrm{C}$

\begin{tabular}{|c|c|c|c|c|}
\hline \multirow{3}{*}{$\begin{array}{l}\text { Hydrolysis time, } \\
\text { weeks }\end{array}$} & \multicolumn{3}{|l|}{ Analysis of SC } & \multirow{3}{*}{$\begin{array}{l}\mathrm{pH} \text { of } \\
\text { hydrolysis } \\
\text { medium }\end{array}$} \\
\hline & \multirow[t]{2}{*}{ Weight loss, \% } & \multicolumn{2}{|l|}{ DSC, I run } & \\
\hline & & $T_{m},{ }^{\circ} \mathrm{C}$ & $\Delta H_{m}, \mathrm{~J} \mathrm{~g}^{-1}$ & \\
\hline 1 & 0.3 & $203.1(198.7)$ & 98.9 & 6.9 \\
\hline 2 & 4.3 & 197.1 & 96.2 & 6.3 \\
\hline 4 & 12.9 & 195.8 & 100.7 & 5.4 \\
\hline 8 & 20.1 & 191.8 & 107.8 & 4.7 \\
\hline 16 & 28.1 & 185.5 & 106.5 & 4.0 \\
\hline
\end{tabular}

${ }^{\text {a }}$ Phosphate buffer with starting $\mathrm{pH}=7.4$ was used for hydrolysis 
Because for the experiment at higher temperature the microparticles were applied which were smaller and much more regular than those used in the experiment at $37{ }^{\circ} \mathrm{C}$, the hydrolysis rate of both experiments cannot be compared. As we can see from the data presented in Table 3, microparticles used for the fast hydrolysis had a higher degree of crystallinity (higher $\Delta H_{m}$ values) than large particles used in the previous study at $37{ }^{\circ} \mathrm{C}$ which could be assigned to better SC crystallization from THF than from dioxane [21]. On the other hand, they were smaller as it is shown in Fig. 1 and in Table 1. These two factors could cause opposite effect on the hydrolysis rate; however, it seems that the temperature had the predominant influence. The weight loss at $50{ }^{\circ} \mathrm{C}$ reached almost $30 \mathrm{wt} \%$ during 16 weeks of experiment, whereas weight loss at $37^{\circ} \mathrm{C}$ reached about half of this value. Figure 4 illustrates the rate of hydrolysis of PLA SC microparticles at $50{ }^{\circ} \mathrm{C}$ (Fig. 5).

Because hydrolytic degradation during the same time was more advanced at $50{ }^{\circ} \mathrm{C}$ leading to shorter polymer chains, also the melting temperature of PLA material dropped more quickly reaching $\sim 180{ }^{\circ} \mathrm{C}$ after 16 weeks, whereas $T_{m}$ of SC hydrolyzed during the same time at $37{ }^{\circ} \mathrm{C}$ was about $205{ }^{\circ} \mathrm{C}$. Similarly, as it was observed in the case of hydrolysis performed at $37^{\circ} \mathrm{C}$, melting enthalpy of stereocomplex/CaO increases with the hydrolysis progress and only after the significant PLA degradation-decreases.

As it was mentioned, hydrolysis was performed without buffer exchange which means that hydrolysis products accumulated in the hydrolysis medium. The main products of polylactide hydrolysis are lactic acid and linear lactic acid oligomers [12]. Carboxyl groups catalyze hydrolysis process, pronouncing further PLA degradation. The increasing acidity of the hydrolysis medium is evident from measured $\mathrm{pH}$ values presented in Table 3 . As we can see, $\mathrm{pH}$ from the starting value of 7.4 characteristic for used phosphate buffer dropped to the value of $\sim 4$ after 16 weeks of the experiment. ${ }^{1} \mathrm{H}$ NMR analysis and mass spectrometry (chemical ionization) of the hydrolysis medium after the different time of the process

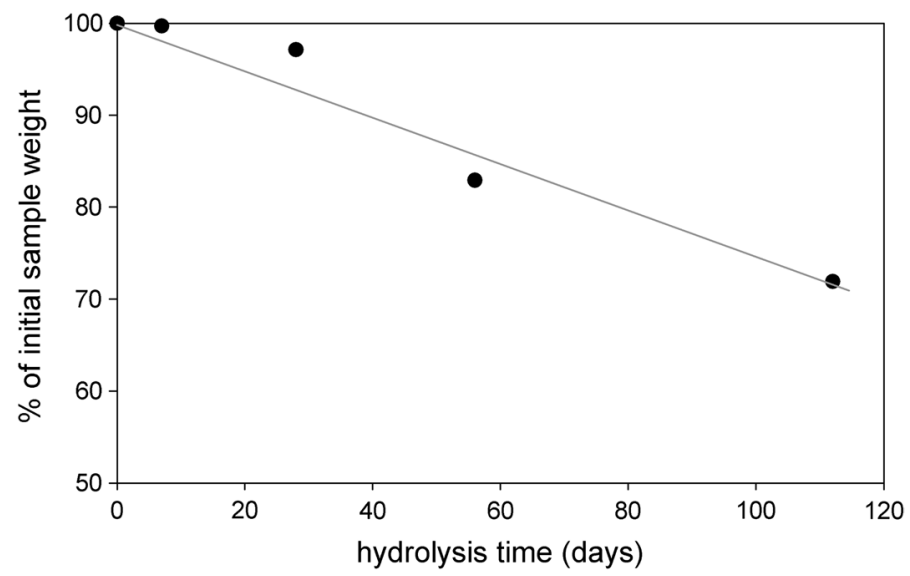

Fig. 5 The dependence of weight loss on time for $\mathrm{SC} / \mathrm{CaO}$ during hydrolysis performed at $50{ }^{\circ} \mathrm{C}$ 
indicated, as expected, mainly the presence of the lactic acid. (Representative ${ }^{1} \mathrm{H}$ NMR and MS CI spectra are presented in Supplementary Information).

PLA degradation was supposed to be accompanied by the microparticles destruction which was confirmed by the observation of the changes of SC morphology before and after hydrolytic degradation experiment performed at $50{ }^{\circ} \mathrm{C}$ (see Fig. 6).

As it can be noticed in SEM pictures, the relatively uniform spherical (although porous) microparticles before hydrolysis completely lost their spherical structure during 16 weeks of hydrolysis. It seems that the destruction of microparticles proceeded in the whole volume of the microparticle and the porous structure enabled water penetration. The bulk erosion of small devices, also microparticles was postulated earlier by other authors (larger devices degrade from the core) [7].

Because a significant drop of melting temperature up to the value close to that characteristic for one stereoisomer [43] was observed in the experiment at elevated temperature, it was interesting if the microparticles disintegration was accompanied by the SC decomposition. To clarify the situation, stereocomplex samples were analyzed by FTIR spectroscopy.

As it can be seen in Fig. 7, in IR spectra in the wavelength range $850-980 \mathrm{~cm}^{-1}$, the signals characteristic to stereocomplex $[18,44]$ appear in the same shape for the sample after 16 weeks of hydrolysis (when almost $30 \%$ of PLA degraded) as for the sample before hydrolysis. Thus, hydrolysis which at early stages caused mainly the degradation of the amorphous phase affected only slightly crystalline stereocomplex domains. The observed decrease in melting temperature could be possibly assigned to the presence of less perfect SC crystals due to the PLA chains scission.

\section{Conclusions}

Although hydrolysis of PLA stereocomplex has been already investigated and described by many authors, the behavior of SC in a form of microparticles containing metal ions inside, exposed to hydrolytic medium provides new information. Microspheres prepared from PLA stereocomplex precipitated in the presence of calcium cations have crystallinity degree comparable or slightly higher than that of low molecular weight PLLA used for stereocomplexation which depends on conditions
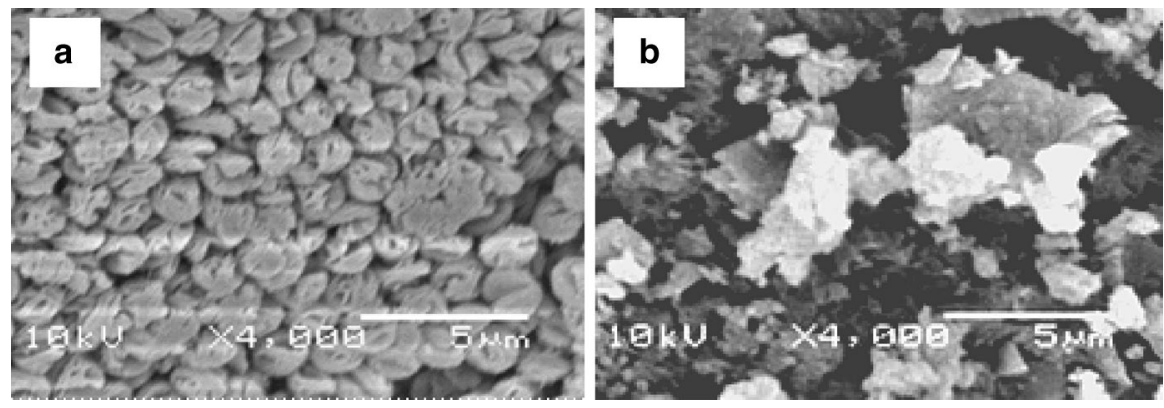

Fig. 6 SEM pictures of SC/CaO: a before hydrolysis and $\mathbf{b}$ after 16 weeks of hydrolysis at $50{ }^{\circ} \mathrm{C}$ 


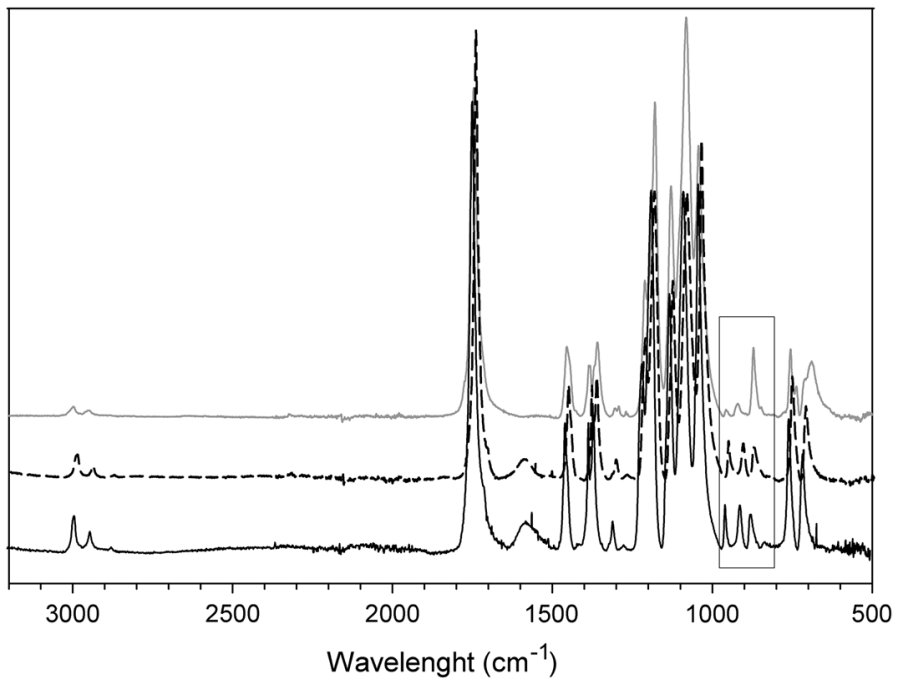

Fig. 7 IR spectra of $\mathrm{SC} / \mathrm{CaO}$ after 16 weeks of hydrolysis performed at $50{ }^{\circ} \mathrm{C}$ (solid line) and before hydrolysis (dashed line). Additionally, IR spectrum of PLLA used for stereocomplexation is shown (gray line). In the box signals characteristic for stereocomplex or alternatively for PLA stereoisomer are visible

of the stereocomplex preparation, in the case of studied systems-on the solvent. However, the crystallinity is lower than the initial crystallinity of stereocomplex prepared without calcium oxide. This lower crystallinity and additionally ionization of carboxyl groups facilitate hydrolysis, which proceeds faster in the case of SC microspheres containing $\mathrm{Ca}^{2+}$ than hydrolysis of SC alone not forming spherical particles. The gradual decomposition of microspheres and degradation of PLA material during the hydrolysis experiment are promising effects for slow release of the pharmaceutical agent in the potential microparticles application as drug carriers. Numerous polylactide-based drug delivery systems described in the literature often require multi-step preparation procedures $[26,27]$. The advantage of the approach presented in this contribution is its simplicity, polylactide microparticles containing calcium ion (thus ionic groups promoting self-organization) are formed spontaneously upon mixing of components in the simple experimental set-up. An additional advantage is the presence of calcium ions which is known to show synergistic effect with some biologically active compounds (such as vitamin D3 and calcium [45]).

Acknowledgements The authors gratefully acknowledge financial support from the National Science Centre, Grant No. 2013/11/B/ST5/01618.

Open Access This article is distributed under the terms of the Creative Commons Attribution 4.0 International License (http://creativecommons.org/licenses/by/4.0/), which permits unrestricted use, distribution, and reproduction in any medium, provided you give appropriate credit to the original author(s) and the source, provide a link to the Creative Commons license, and indicate if changes were made. 


\section{References}

1. Tsuji H (2010) Hydrolytic degradation. In: Auras R, Lim LT, Selke SEM, Tsuji H (eds) Poly(lactic acid): synthesis, structures, properties, processing, and applications. Wiley, Hoboken, pp 345-381

2. Tsuji H, Saeki T, Tsukegi T, Daimon H, Fuije K (2008) Comparative study on hydrolytic degradation and monomer recovery of poly(L-lactic acid) in the solid and in the melt. Polym Degrad Stabil 93:1956-1963

3. Hakkarainen M, Albertsson A-C (2008) Degradation products of aliphatic and aliphatic-aromatic polyesters. Adv Polym Sci 211:85-116

4. Li SM (1999) Hydrolytic degradation characteristics of aliphatic polyesters derived from lactic and glycolic acids. J Biomed Mater Res 48:342-353

5. Tsuji H, Ikada Y (1998) Properties and morphology of poly(L-lactide). II. Hydrolysis in alkaline solution. J Polym Sci A: Polym Chem 36:59-66

6. Tsuji H, Ikada Y (1997) Blends of crystalline and amorphous poly(lactide) III. hydrolysis of solution-cast blend films. J Appl Polym Sci 63:855-863

7. Grizzi I, Garreau H, Li S, Vert M (1995) Hydrolytic degradation of devices based on poly(DL-lactic acid) size-dependence. Biomaterials 16:305-311

8. Karst D, Yang Y (2008) Effect of arrangement of L-lactide and D-lactide in poly[(L-lactide)-co-(Dlactide)] on its resistance to hydrolysis studied by molecular modeling. Macromol Chem Phys 209:168-174

9. Hakkarainen M, Albertsson AC, Karlsson S (1996) Weight losses and molecular weight changes correlated with the evolution of hydroxyacids in simulated in vivo degradation of homo- and copolymers of PLA and PGA. Polym Degrad Stabil 52:283-291

10. Tsuji H, Fukui I (2003) Enhanced thermal stability of poly(lactide)s in the melt by enantiomeric polymer blending. Polymer 44:2891-2896

11. Tsuji H, Ikada Y (1999) Stereocomplex formation between enantiomeric poly(lactic acid)s. XI. Mechanical properties and morphology of solution-cast films. Polymer 40:6699-6708

12. Andersson SR, Hakkarainen M, Inkinen S, Södergård A, Albertsson A-C (2010) Polylactide stereocomplexation leads to higher hydrolytic stability but more acidic hydrolysis product pattern. Biomacromolecules 11:1067-1073

13. Tsuji H (2002) Autocatalytic hydrolysis of amorphous-made polylactides: effects of L-lactide content, tacticity, and enantiomeric polymer blending. Polymer 43:1789-1796

14. Tsuji H (2000) In vitro hydrolysis of blends from enantiomeric poly(lactide)s: part 1. Well-stereocomplexed blend and nonblended films. Polymer 41:3621-3630

15. Tsuji H, Tsuruno T (2010) Accelerated hydrolytic degradation of poly(L-lactide)/poly(D-lactide) stereocomplex up to late stage. Polym Degrad Stab 95:477-484

16. Tsuji H (2005) Poly(lactide) stereocomplexes: formation, structure, properties, degradation, and applications. Macromol Biosci 5:569-597

17. Arias V, Odelius K, Albertsson A-C (2014) Nano-stereocomplexation of polylactide (PLA) spheres by spray droplet atomization. Macromol Rapid Commun 35:1949-1953

18. Biedron T, Brzezinski M, Biela T, Kubisa P (2012) Microspheres from stereocomplexes of polylactides containing ionic liquid end-groups. J Polym Sci A Polym Chem 50:4538-4547

19. Brzezinski M, Biela T (2015) Micro- and nanostructures of polylactide stereocomplexes and their biomedical applications. Polym Int 64:1667-1675

20. Michalski A, Makowski T, Biedron T, Brzezinski M, Biela T (2016) Controlling polylactide stereocomplex (sc-PLA) self-assembly: from microspheres to nanoparticles. Polymer 90:242-248

21. Bednarek M, Wojtczak E, Pluta M (2017) Spontaneous formation of polylactide stereocomplex microspheres containing metal ions. Polym Int 66:108-118

22. Pinto Reis C, Neufeld RJ, Ribeiro AJ, Veiga F (2006) Nanoencapsulation I. Methods for preparation of drug-loaded polymeric nanoparticles. Nanomed Nanotech Biol Med 2:8-21

23. Kataoka K, Harada A, Nagasaki Y (2012) Block copolymer micelles for drug delivery: design, characterization and biological significance. Adv Drug Deliv Rev 64:37-48

24. Pagels RF, Prudhomme RK (2015) Polymeric nanoparticles and microparticles for the delivery of peptides, biologics, and soluble therapeutics. J Control Release 219:519-535

25. Piluso S, Soultan AH, Patterson J (2017) Molecularly Engineered Polymer-Based Systems in Drug Delivery and Regenerative Medicine. Curr Pharm Design 23:281-294 
26. Lassalle V, Ferreira ML (2007) PLA nano- and microparticles for drug delivery: an overview of the methods of preparation. Macromol Biosci 7:767-783

27. Lee BK, Yun Y, Park K (2016) PLA micro- and nano-particles. Adv Drug Deliv Rev 107:176-191

28. Sah H, Thoma LA, Desu HR, Sah E, Wood GC (2013) Concepts and practices used to develop functional PLGA-based nanoparticulate systems. Int J Nanomed 8:747-765

29. Khan I, Gothwal A, Sharma AK, Kesharwani P, Gupta L, Iyer AK, Gupta U (2016) PLGA nanoparticles and their versatile role in anticancer drug delivery. Crit Rev Ther Drug 33:159-193

30. Mohammadi-Samani S, Taghipour B (2015) PLGA micro and nanoparticles in delivery of peptides and proteins; problems and approaches. Pharm Dev Technol 20:385-393

31. Singh NK, Lee DS (2014) In situ gelling pH- and temperature-sensitive biodegradable block copolymer hydrogels for drug delivery. J Control Release 193:214-227

32. Zhao L, Li N, Wang K, Shi C, Zhang L, Luan Y (2014) A review of polypeptide-based polymersomes. Biomaterials 35:1284-1300

33. Ohya Y, Takahashi A, Nagahama K (2012) Biodegradable polymeric assemblies for biomedical materials. Adv Polym Sci 247:65-114

34. Kumar G, Shafiq N, Malhotra S (2012) Drug-loaded PLGA nanoparticles for oral administration: fundamental issues and challenges ahead. Crit Rev Ther Drug 29:149-182

35. Saffer EM, Tew GN, Bhatia SR (2011) Poly(lactic acid)-poly(ethylene oxide) block copolymers: new directions in self-assembly and biomedical applications. Cur Med Chem 18:5676-5686

36. Dinarvand R, Sepehri N, Manoochehri S, Rouhani H, Atyabi F (2011) Polylactide-co-glycolide nanoparticles for controlled delivery of anticancer agents. Int J Nanomed 6:877-895

37. Bertin A (2012) Emergence of polymer stereocomplexes for biomedical applications. Macromol Chem Phys 213:2329-2352

38. Liu R, He B, Li D, Lai Y, Tang JZ, Gu Z (2012) Stabilization of pH-sensitive mPEG-PH-PLA nanoparticles by stereocomplexation between enantiomeric polylactides. Macromol Rapid Commun 33:1061-1066

39. Hu J, Tang Z, Qiu X, Han Y, Du Q, Chen X, Jing X (2005) Effects of stereoregularity of multiblockcopoly(rac-lactide)s on stereocomplexmicroparticles and their insulin delivery. Macromol Biosci 5:1193-1199

40. Slivniak R, Domb AJ (2002) Stereocomplexes of enantiomeric lactic acid and sebacic acid esteranhydride triblock copolymers. Biomacromolecules 3:754-760

41. Schwach G, Coudane J, Engel R, Vert M (2002) Influence of polymerization conditions on the hydrolytic degradation of poly(DL-lactide) polymerized in the presence of stannous octoate or zincmetal. Biomaterials 23:993-1002

42. Mayer JM, Allen AL, Dell PA, McCassie JE, Shupe AE, Stenhouse PJ, Welch EA, Kaplan DL (1993) Development of biodegradable materials_-balancing degradability and performance. Abst Pap ACS 205:466

43. Migliaresi C, Cohn D, Lollis DE, Fameri L (1991) Dynamic mechanical and calorimetric analysis of compression-molded PLLA of different molecular weights: effect of thermal treatments. J Appl Polym Sci 43:83-95

44. Zhang J, Duan Y, Sato H, Tsuji H, Noda I, Yan S, Ozaki Y (2005) Crystal modifications and thermal behavior of poly(L-lactic acid) revealed by infrared spectroscopy. Macromolecules 38:8012-8021

45. Ross AC, Taylor CL, Yaktine AL, Del Valle HB (2011) Dietary reference intakes for calcium and vitamin D. Committee to Review Dietary Reference Intakes for Vitamin D and Calcium; Institute of Medicine, National Academies Press, Washington DC 